\title{
The Role of Human Resource in Ethics and Compliance Programs
}

\author{
Valeriu Deciu \\ Alexandru Ioan Cuza University, Iasi, Romania \\ Email: deciuvaleriu@gmail.com
}

How to cite this paper: Deciu, V. (2022). The Role of Human Resource in Ethics and Compliance Programs. Psychology, 13, 221232 .

https://doi.org/10.4236/psych.2022.132012

Received: November 1, 2021

Accepted: February 12, 2022

Published: February 15, 2022

Copyright (c) 2022 by author(s) and Scientific Research Publishing Inc. This work is licensed under the Creative Commons Attribution International License (CC BY 4.0).

http://creativecommons.org/licenses/by/4.0/ (c) (i) Open Access

\begin{abstract}
Ethics and compliance programs are significantly important for companies and business organizations. That is because they stipulate the regulations that the companies must follow in order to operate lawfully. Failure to adhere to the ethics and compliance regulations may spell doom for a business. For instance, it may lead to litigation issues. Companies may also damage their public images by engaging in unethical behavior. As such, organizations must try their best to ensure employees are compliant. The human resource department is often in a suitable position to ensure compliance. That is because they manage employees, and influence employee behavior. The aim of this study is to prove that human resource departments can promote adherence to ethics and compliance programs. Through the use of a qualitative study in the form of a literature review, the research proves that human resource departments have significant control over compliance. That is because they can influence employee behavior in a variety of ways as well as regulate the recruitment process. As a result, they can create an environment that favors compliance that is filled with individuals with a keen interest in working professionally.
\end{abstract}

\section{Keywords}

Ethics and Compliance, Human Resource, Employee Motivation, Rewards, Punishment, Reporting

\section{Introduction}

The essence of ethics and compliance programs is to eliminate the possibility of employee misconduct. Employee misconduct is when employees fail to follow the moral, legal, and ethical obligations governing their practice, resulting in potential repercussions for their organizations. For instance, employees may use work hours inappropriately, resulting in losses for their companies. Alternative- 
ly, they may fail to follow legal requirements, causing their companies to suffer lawsuits. Although it is within the best interest of companies that their stakeholders adhere to ethics and compliance guidelines, there are many challenges that inhibit compliance. For instance, it may be difficult for organizations to monitor all employees to ensure they are compliant. Employees may also not report observed misconduct for a variety of reasons, allowing wrong deeds to take place. That is where the human resource department comes into play. Considering that the human resource department is in charge of managing employees, they can create working environments that promote positive conduct. Ideally, the human resource department is indispensable to organizations when it comes to determining ethics and regulatory compliance. Therefore, the focus of the research will be to highlight the essential changes in the human resource department to improve adherence to ethics and compliance guidelines. The aim is to prove that human resource departments can improve adherence to ethics and compliance measures by creating environments that make it easier for employees to follow rules. The study will be qualitative and will rely on the review of secondary resources to formulate its conclusions. Eventually, it will prove that the human resource department is indispensable when it comes to compelling employees to operate within specific constructs.

\section{Background}

Ethics and compliance programs have a significant role to play in professional organizations. That is because they ensure everyone within the organization follows the ethical, legal, and moral obligations required of them by their practice. Typically, company activities are subject to a wide array of regulations (Calderon, Piñero, \& Redín, 2018). In addition, businesses may have their own moral and ethical guidelines that ensure maximum productivity while the company maintains its public reputation. When companies follow their internal moral and ethical regulations, they maintain their identity. Therefore, when companies have comprehensive ethics and compliance programs, they are bound to accrue significant benefits.

However, most companies may neglect ethics and compliance programs because they cost the companies money without generating any income. Such a position is short-sighted, since an ethics and compliance breach could result in significant challenges (Bell, 2020). For instance, a business may be subject to litigations when they fail to follow the legal obligations controlling their scope of operations. Businesses may also destroy their public reputation, negatively impacting their market share and public image (Bell, 2020).

An example of how non-compliance to ethics and operational regulations affects revenue collection is evident from the Volkswagen Company. The organization failed to follow greenhouse emission guidelines, causing it to have a negative public reputation (Bell, 2020). Aside from the direct costs associated with changing their operational procedures, Volkswagen also suffered litigation costs, 
and lost a lot of time in legal battles. The company's sales also dropped, indicating that negative public reputation is significantly detrimental to business organizations.

Such damages will definitely impact revenue collection, indicating that the failure to follow ethics and compliance measures is self-defeating for business organizations. Therefore, it is pertinent for business organizations to invest their time and efforts in ensuring all relevant stakeholders follow ethics and compliance guidelines. However, how can businesses achieve that? Even though organizations may require their supervisors to keep a close eye on all employee activities, there are still significant challenges in ensuring compliance. For instance, it is impossible for supervisors, who are outnumbered by employees, to keep track of every employee and their activities (Calderon, Piñero, \& Redín, 2018).

In addition, studies indicate that most of the persons engaged in ethics and compliance misconduct work in administrative positions (Li \& Raghunandan, 2021). Although employees may be aware of the misconduct, they rarely report. Therefore, even though organizations may have comprehensive and well-formulated ethics and compliance guidelines, it is impossible for them to ensure all stakeholders remain compliant.

The best solution for companies when they wish their employees to comply with ethics and compliance guidelines is for them to involve the human resource department. The human resource department oversees managing employees, and that puts it at a position to improve reporting in the event of ethical misconduct (Li \& Raghunandan, 2021). The human resource department could also promote adherence to ethics and compliance guidelines by rewarding employees for proper conduct. Essentially, there are many ways that the human resource department can influence compliance. Therefore, by evaluating academic literature on the roles of the human resource department in ensuring ethical compliance, the research will prove that the human resource department is crucial in determining adherence.

\section{Methodology}

The objective of this research will be to prove that through the proper measures human resource department can help improve adherence to ethics and compliance guidelines within organizations. In order to prove the hypothesis, the study will take a qualitative approach. The research will be qualitative since it will rely on descriptive data to ascertain the essence of the human resource department in determining regulations compliance. The research will also rely on an explanatory approach, which will focus on explaining the essence of the human resource department in ethics and compliance programs adherence.

Through the use of secondary resources, the research will formulate its findings. There is a lot of existing literature documenting the essence of the human resource department in ethics and compliance programs. Therefore, by focusing on academic and accredited resources on the topic, the study will show how the 
human resource can help streamline compliance to regulatory measures. All sources will be from within the past five years, and that is to ensure they provide information that is relevant.

The research will collect relevant information through a literature review, which is followed by a discussion section that analyzes the findings. As such, the study will rely on critical evaluation procedures to gain more insight on the topic. The most probable obstacle in the research activity will be selecting the source materials. That is because the sources must be credible, from within the past five years, and relevant to the topic. However, using scholarly databases, it will be possible to obtain sources that fulfil the requirements. For instance, the Google Scholar search engine will make it possible to query searches based on keywords that will provide suitable results. The search engine also permits the filtering of results based on time, and that will ensure that all articles are from within the past five years. The study will only consider sources that are peer-reviewed, and those from authors with considerable authority over the topic of study. Finally, it will be essential to read through the sources before their inclusion, to ensure they provide information that is relevant for the study.

\section{Literature Review}

\subsection{Create and Enforce Ethical Guidelines}

According to research evidence, when employees are aware of the minimal standards of conduct and compliance to ethical obligations, they are more likely to report those who deviate (Haugh, 2021). The study showed that in companies where the human resource department set minimum standards, employees were 32\% more likely to indicate the human resource department about unethical conduct compared to those that did not set minimum requirements. In addition, the companies should clearly indicate the behaviors that qualify as misconduct. The essence of doing so is that it lets employees realize when their colleagues engage in misconduct (Haugh, 2021). As such, they can report the behavior to the appropriate authorities.

In addition to creating ethical guidelines, the human resource departments should begin employee training during the onboarding process. When employees learn about the company's expectations during the onboarding process, they will have a better understanding of what the administration requires of them, improving their probability of considering ethics and compliance programs to be of priority (Remišová, Lašáková, \& Kirchmayer, 2019). Therefore, in the event of misconduct, they will potentially report.

Also, to ensure that employees are always keen on ethics, the human resource department should make ethics and compliance program discussions regular and explorative. Study findings indicate that when employees see regular and consistent communication about ethics, they are more likely to practice proper conduct (Bisel, 2017). For instance, the human resource department could take the initiative to issue frequent mobile messages to employees that remind them of the company's 
values, ethics, and expected conduct.

In addition, organizations should take time to recognize employees for proper conduct. When organizations show their employees that they appreciate their good behavior, employees will learn that compliance to the regulatory guidelines is never in vain (Haugh, 2021). Given that the human resource department also manages administrative employees, frequent communication and feedback will improve their probability of reporting misconduct while lowering their chances of being implicit in irregular business activities.

\subsection{Prioritize the Professional Development of the Employees}

The human factor is essential to the success of business organizations. They influence whether a business will acquire competitive advantage over rivals. That is because the human factor controls all aspects of a business. They influence the shape of interactions, organizational culture, work ethic, compliance to regulatory guidelines, as well as the levels of productivity (Bisel, 2017). Therefore, it is essential for business organizations to ensure that their employees are professional enough to guarantee the desired goals, vision, and mission of their organization.

Therefore, if companies wish to improve their performance, they must ensure their human power is empowered, competent, and has high levels of integrity (Bell, 2020). The better the human resource department empowers its employees, the more it increases their chances of gaining competitive advantage. For instance, when an organization consistently trains its employees to become professional, the more likely they are to follow the stipulated ethics and compliance guidelines.

Ideally, professionalism refers to the quality of employees to demonstrate competence and adherence to the regulations governing their professions (Haugh, 2021). Regardless of whether there are protocols to monitor irregular behavior, professional employees will always conduct themselves ethically. That is because they possess important qualities that allow them to perform at elevated levels.

For instance, one of their qualities is the ability to learn. For employees to become competent at their jobs, they must master the essential knowledge and skill set (Wasserman, 2017). Some of the things they will have to learn are technical, while others are learned vertically through engaging with persons from other departments in their company. In addition, they must also learn the rules and regulations that govern their practice, especially if persons are in careers that require licensing (Wasserman, 2017).

As such, the human resource department must start considering open-minded individuals from the recruiting level. At the same time, they must focus on selfregulated individuals, who may take charge and learn for themselves. Although the human resource department must develop ethics and compliance education program, it is only when the employees have personal drive that they can achieve significant things (Haugh, 2021). Finally, organizations must create cultures that 
permit employees to express themselves, so that they can engage in new learning curves that will permit them to develop professionally.

Professional employees are also significantly conscientious. Conscientiousness is a trait that compels individuals to feel the desire to accomplish their duties accurately and thoroughly (Bell, 2020). As such, persons with high levels of conscientiousness are highly reliable, hard-working, organized, and with a lot of emphasis on detail. Their reliability will ensure that they follow through with ethics and compliance measures, eliminating significant worry in their business organizations.

The same way that organizations should consider those with an ability to learn during recruitment processes, they must also ensure that their workforce is made up of highly conscientious individuals. Since it is almost impossible to teach the quality, employing persons with a track record of reliability may be the better option (Bisel, 2017). That is because they are naturally drawn towards doing the right thing, and that minimizes stress for their organizations.

\subsection{Punish Improper Conduct}

Perhaps there is no better way for organizations to ensure their personnel are compliant to rules and regulations than to punish misconduct. It is candid that the lack or the presence of punishment influences organizational culture (Gaillard \& DeCorte, 2020). That is because, when organizations permit improper conduct to go without punishment, they create an environment characterized by laxity. Employees will feel free to disregard the ethics and compliance measures because they understand that they will not suffer any consequences for their misdoing.

At the California State University, the human resource department was not proactive in punishing misconduct. As a result, some of the staff saw the laxity demonstrated by the human resource department as an opportunity to do things as they desired. For an extensive period, the employees took excess work breaks, which ended up costing the university in excess of $\$ 111,000$ (Howle, 2018). The case makes it apparent that failure to punish misconduct promotes unethical conduct.

At the same time, failure to enforce punitive measures discourages reporting behavior among the employees (Wasserman, 2017). Consider an instance where a company fails to punish wrongdoers despite multiple reports of their misconduct. The employees who report the cases will feel that their efforts are unappreciated, causing them to ignore future wrongdoing (Wasserman, 2017). Some employees have a higher degree of duty than others, and it is pertinent for human resource departments to ensure that the efforts of diligent employees are not taken for granted. By punishing misconduct, they will encourage those who are serious about their work. By weeding out the bad employees, human resource departments will ensure the success of their companies by promoting professional corporate culture. 


\subsection{Rewards}

Human resource departments must also consider the essence of rewards in motivating employees to perform as expected. According to studies, employees who are appreciated by their organizations tend to work harder than those who do not gain any recognition (Remišová, Lašáková, \& Kirchmayer, 2019). Therefore, human resource departments must design recognition and rewarding programs that guarantee monetary gains, bonuses to employees who help the organization achieve its goals.

Rewards are beneficial because they help improve employee morale. When employees are happy, they are more likely to perform better, as well as remain committed to their organization (Remišová, Lašáková, \& Kirchmayer, 2019). Studies indicate a high correlation between rewards and productivity. That is because they cause employees to work harder, making them more productive. When employees understand that the human resource department will acknowledge and appreciate their actions, they are drawn to conduct themselves accordingly.

As per studies in the United States, 79\% of 10,000 respondents from more than 500 companies indicated that rewards compel them to work harder (Ndungu, 2017). Current human resource trends indicate that rewards are becoming all the more essential in work environments. That is because Millennials and Generation $\mathrm{Z}$ employees have high preference for fulfilling and meaningful work environments (Haugh, 2021). Therefore, it is imperative that human resource departments in companies consider reward systems that will compel their employees to work harder.

Rewards also help employees to find satisfaction in their job activities. When diligent employees are rewarded for their proper conduct, they develop better satisfaction in their work (Ndungu, 2017). When employees are happy, their productivity increases, and they are also more likely to abide by the rules and regulations governing their practice. When they are appreciated, their trust increases. It becomes easier for them and their organizations to trust each other, meaning it will be likelier for them to follow ethics and compliance guidelines. Compared to punishment, reward is a better motivating factor, and since all employees would desire the benefits of proper conduct, they will most likely attempt to outperform each other. Therefore, they will spur their organizations to perform better.

\subsection{Assessments to Identify Factors that Promote Ethical Conduct}

Frequent workplace assessments may also prove imperative in promoting adherence to ethics and compliance measures. Occasionally, an employee will fail to adhere to the set rules. However, how will organizations realize that there are compliance issues? Also, how will they mitigate similar issues from recurring in the future? Through the frequent assessment of ethics and compliance issues to determine when they occur and factors that influence their occurrence, it will be possible for organizations to control their frequency. When organizations assess whether their employees are compliant, they will identify the bad apples, making 
it possible for them to enforce punitive measures that will reduce their occurrences (Li \& Raghunandan, 2021). Perhaps more essential is the identification of factors that promote improper conduct. The presence of loopholes within a business organization may compel employees to act in selfish ways, jeopardizing the position of their companies. For instance, the failure to punish offenders by the California State University caused its employees to use work hours for personal businesses, and that ended up significantly impacting the operations of the institution (Howle, 2018). In the case of the university, the human resource department failed to conduct frequent assessments on ethics and compliance measures. As such, they failed to realize instances of wrongdoing, and that ended up causing severe detriment to their organization. Had they been a little bit keener, they would have realized the misconduct and the gaps facilitating the negative behaviors. Therefore, they would have responded sooner, avoiding the significant financial loss they incurred from the incompetence of their staff. Through assessments, companies can potentially adjust their environment to ensure the best outcomes. They can also understand factors that promote proper conduct by evaluating the model employees, and that will help them develop conditions that promote the best out of anyone.

\subsection{Proper Environment for Reporting Unethical Conduct}

Thus far, it is apparent that reporting plays a significant role in influencing adherence to ethics and compliance measures. When companies punish reported law offenders, the persons filing the reports are more likely to report other people who disregard the ethics and compliance measures of their organization (Ndungu, 2017). Therefore, the employees that are in the organization will take the rules and regulations governing their operations more seriously, resulting in better compliance measures. At the same time, reporting also promotes compliance since it discourages employees from engaging in misconduct (Bell, 2020). When human resource departments ensure employees have a conducive environment to report, the rate of reporting is bound to increase. Therefore, potential law offenders will keep their actions in check because they understand that they will potentially face repercussions if they fail to follow the rules and operational guidelines of their organizations.

It is essential for human resource departments to create proper reporting environments. A proper reporting environment is one that permits anonymity (Gaillard \& DeCorte, 2020). One of the reasons employees may fail to report misconduct is because they may fear consequences associated with their reporting. According to surveys, many of the employees associated in improper conduct occupy administrative positions (Bell, 2020). Considering that such persons have significant control and power over junior employees, it may be more challenging for junior employees to report their wrongdoings to human resource personnel. That is because they may jeopardize their position in the company by reporting their seniors. Therefore, to ensure that junior employees do not experience challenges reporting unethical conduct, there must be anonymous avenues for them 
to file complaints.

Organizations must also ensure that they have a safe and open reporting culture. A safe and just reporting culture is one that respects all cultures and gives employees the ample time and space to express themselves (Haugh, 2021). It is potential that reporting activities may be affected by human error, discriminative perspectives, or interpersonal misunderstandings. Therefore, if organizations react to reports without validating credibility, they may fall implicit to poor reporting trends. As such, the reporting practices must be based on accountability, and they must promote a corporate business culture that benefits all employees. In addition to the use of a just culture in reporting, organizations must also rely on retributive culture (Bell, 2020). Essentially, a retributive culture is one that is entirely based on rules. Upon the violation of the rules, persons may be liable to face penalties. Using a retributive reporting culture, businesses will clearly indicate why some practices must be reported to the human resource department.

At the same time, human resource organizations must provide employees with a fast and convenient means of making reports. Physically going to the human resource department to file issues may be an arduous procedure, and that calls for the use of digital platforms in reporting (Wasserman, 2017). Presently, almost the entirety of the world is connected to the internet, and with the use of mobile or desktop devices, employees can report whatever improper conduct they may have observed. Not only will digital devices streamline reporting activities, but they will also encourage reporting since employees can do so from the comfort of their spaces and while maintaining their identities private. The online platforms can also incorporate follow-up details to ensure employees understand what happens following their reports (Bell, 2020). The human resource department should clearly make reports on the actions they took against the defendant, and whether they were found guilty or not. The essence of such practice is that the human resource department will show employees that they seriously take their considerations.

\subsection{Consider Employee Background}

There is nothing that will tell an organization more about an employee than their previous work records. Of course, it is possible for persons to falsify their resumes and personalities during interviews. Therefore, how will organizations ensure that their employees are professionals with high levels of integrity? The best approach for companies is to pay special attention to employee track record (Remišová, Lašáková, \& Kirchmayer, 2019). By contacting previous employers for instance, the human resource department can evaluate whether potential employees have previously been implicated in ethics and compliance misconduct.

The essence of studying the background of employees before permitting them onboard is because it gives their employers privy about their personalities. Ideally, personality determines the way an individual will behave over the course of 
their lifetime (Calderon, Piñero, \& Redín, 2018). Therefore, if an individual has a history of irrationality and disregard for laws, it is likelier that they may engage in similar activities in the future. As such, improper conduct should be a red flag for recruitment personnel. However, instead of evaluating whether employees might have engaged in reckless activities, it is imperative for business organizations to target employees with impeccable histories (Haugh, 2021).

It is essential for human resource departments to consider the employees who have demonstrated incredible levels of competence and professionalism over the course of their careers, since they are the ones that will guarantee improved performance measures. High performing employees will easily integrate into their new working environments, and they will also help improve the levels of excellence within companies since they have a lot to offer (Calderon, Piñero, \& Redín, 2018). As such, it is essential for human resource departments to conduct extensive research on their employees before hiring.

\section{Discussion}

Ideally, the objective of this research was to prove that the human resource department within organizations can significantly promote adherence to ethics and compliance guidelines. Thus far, it is apparent that although the repercussions stemming from non-compliance may force an organization to follow rules and regulations, it is the human resource department that is at the helm of controlling adherence. That is the human factor plays a huge role in determining the success of an organization, even though they are not the ones who directly benefit or suffer detriment on behalf of their organizations. For instance, improper use of work hours will not have direct negative consequences for the individual employees, but they will definitely hurt their organization. Therefore, it is essential that the human resource department ensures all its employees follow ethics and compliance guidelines since they are the ones capable of impacting the employees.

For starters, human resource departments can promote adherence to ethics and compliance guidelines by creating and enforcing ethical guidelines. When organizations clearly set standards that govern employee conduct, it becomes possible easier for employees to identify misconduct (Haugh, 2021). As a result, they can report misconduct to the human resource departments, which eventually analyze the reported cases before deciding the fitting punishment for the law offender. When companies create and enforce ethical guidelines, they will also make employees aware about the required code of conduct before they even join the organization. As a result, their probability of following the set ethics and compliance guidelines will increase.

The human resource department can also improve adherence to ethics and compliance regulations by developing their employees professionally. Professionalism is an essential ingredient in the making of competent employees, and it is paramount for business organizations to ensure that their employees are compet- 
ing with the best in the industry. Professional employees are those who are competent in their work, have high levels of integrity, and they are also hard working (Remišová, Lašáková, \& Kirchmayer, 2019).

Professionals will willingly follow the ethics and compliance guidelines, saving their organizations a lot of resources in the enforcement of ethics and compliance regulations. It is the duty of human resource departments to ensure that their organizations recruit professionals or highly promising individuals. In addition, companies should also consider developing their employees professionally. Not only will the move ensure compliance to ethical guidelines, but it will also ensure that organizations are more competitive since competent employees will be at a position to create significant benefits.

Human resource departments can also improve adherence to ethics and compliance guidelines by punishing offenders. Punishing law offenders is an effective way of dealing with improper conduct. When employees understand that there will be consequences for their wrongdoings, they are more likely to avoid misconduct (Wasserman, 2017). Aside from discouraging improper conduct, penalties also show the employees that the human resource department is serious about ethics and compliance measures. If persons who break the law face consequences, their colleagues will be more likely to report unethical behavior since they are sure that the organization will react accordingly.

Compared to punishment, rewards are better at motivating employees to conduct themselves accordingly. The essence of rewards is that they make employees feel recognized. It takes a lot to religiously follow rules, and when employees try their best, organizations should reward their actions. Rewards also motivate employees to try harder, and that is the reason it is an important motivating factor for human resource personnel to consider when promoting adherence to ethics and compliance measures. At the same time, organizations must engage in assessment activities to ensure their employees are conducting themselves accordingly. In the event of misconduct, organizations should assess the factors that support the misconduct so that they can make changes in the future. Finally, it is imperative for businesses to consider the background of prospective employees before getting them onboard. The track record will reveal a lot about what an employee is likely to do, enabling human resource departments to determine persons that will best integrate into their organizations.

\section{Conclusion}

The purpose of this study is to reveal that human resource departments could promote adherence to ethics and compliance measures. The research has proved that human resource departments are at the forefront of determining compliance. It is the human factor that controls every aspect of a business, and that means that they are the ones to either follow or disregard ethics and compliance guidelines. Given that it is the job of the human resource department to manage all employees, it means that they can ensure compliance. The human resource department can set an environment that does not permit non-compliance, and that will 
force employees to contemplate ethics and compliance guidelines. By punishing non-compliant employees, for example, the human resource department can ensure there is zero-tolerance for irregular behavior. The human resource department can also increase compliance by recruiting employees with impeccable track records. Considering that the possibility of such persons going against the rules is minimal, companies will have better chances at following ethics and compliance regulations. Ideally, ethics and compliance programs are critical since failure to follow them may inflict significant damages to a company. Therefore, for companies to protect themselves from the potential dangers of non-compliance, it is essential for them to use their human resource departments appropriately.

\section{Conflicts of Interest}

The author declares no conflicts of interest regarding the publication of this paper.

\section{References}

Bell, C. L. (2020). Compliance and Ethics Programs. In R. A. Woellner, J. Voorhees, \& C. L. Bell (Eds.), International Environmental Risk Management (pp. 89-118). CRC Press. https://doi.org/10.1201/9781315166681-7

Bisel, R. S. (2017). Organizational Moral Learning: A Communication Approach. Routledge. https://doi.org/10.4324/9781315652252

Calderon, R., Piñero, R., \& Redín, D. M. (2018). Can Compliance Restart Integrity? Toward a Harmonized Approach. The Example of the Audit Committee. Business Ethics: An European Review, 27, 195-206. https://doi.org/10.1111/beer.12182

Gaillard, M., \& DeCorte, M. J. (2020). Ethics and Workplace Productivity. The Journal of Government Financial Management, 68, 50-52.

Haugh, T. (2021). Leading a Healthier Company: Advancing a Public Health Model of Ethics and Compliance. 58 American Business Law Journal. (Forthcoming) https://doi.org/10.2139/ssrn.3843166

Howle, E. (2018). Investigations of Improper Activities by State Agencies and Employees. Misuse of State Time, Economically Wasteful Activities, and Misuse of State Property. California State Auditor.

Li, X., \& Raghunandan, A. (2021). Institutional Ownership and Workplace Misconduct: Evidence from Federal Labor Law Violations. Social Science Research Network, No. 3460126.

Ndungu, D. N. (2017). The Effects of Rewards and Recognition on Employee Performance in Public Educational Institutions: A Case of Kenyatta University, Kenya. Global Journal of Management and Business Research, 17, 6 p.

Remišová, A., Lašáková, A., \& Kirchmayer, Z. (2019). Influence of Formal Ethics Program Components on Managerial Ethical Behavior. Journal of Business Ethics, 160, 151-166. https://doi.org/10.1007/s10551-018-3832-3

Wasserman, H. (2017). Professionalism and Ethics: The Need for a Global Perspective. Journalism \& Communication Monographs, 19, 312-316.

https://doi.org/10.1177/1522637917734217 